\title{
Self-Powered Safety Helmet Based on Hybridized Nanogenerator for Emergency
}

Long Jin, ${ }^{\dagger, \perp}$ Jun Chen, ${ }^{\S, \perp}$ Binbin Zhang, ${ }^{\dagger}$ Weili Deng, ${ }^{\dagger}$ Lei Zhang, ${ }^{\dagger}$ Haitao Zhang,$^{\dagger}$ Xi Huang, ${ }^{\dagger}$ Minhao Zhu, ${ }^{\dagger, \downarrow}$ Weiqing Yang, ${ }^{* \dagger}$ and Zhong Lin Wang ${ }^{*},, \|$

${ }^{\dagger}$ Key Laboratory of Advanced Technologies of Materials (Ministry of Education), School of Materials Science and Engineering, and $\ddagger$ State Key Laboratory of Traction Power, Southwest Jiaotong University, Chengdu 610031, China

${ }^{\S}$ School of Materials Science and Engineering, Georgia Institute of Technology, Atlanta, Georgia 30332, United States

"Beijing Institute of Nanoenergy and Nanosystems, Chinese Academy of Sciences, Beijing 100083, China

*E-mail: wqyang@swjtu.edu.cn .

*E-mail: zlwang@gatech.edu . 
The power of generator with an external resistance can be expressed as:

$P=I_{S c} \times I_{S C} \times R$

$P_{d}=\frac{P}{V}$

Where $P$ is the power, $I_{s c}$ is the short-circuit current, $R$ is the resistance, and $P_{d}$ is the power density,

$V$ is the volume of the generator. The volume of the generator is $7.7 \mathrm{~cm} \times 4.7 \mathrm{~cm} \times 3.3 \mathrm{~cm}$ $\left(V=0.077 \times 0.047 \times 0.033=1.194 \times 10^{-4} \mathrm{~m}^{3}\right)$. 
Table S1 A list that ranks various materials according to their tendency to gain (negative) or lose electrons (positive) in the contact charging process.

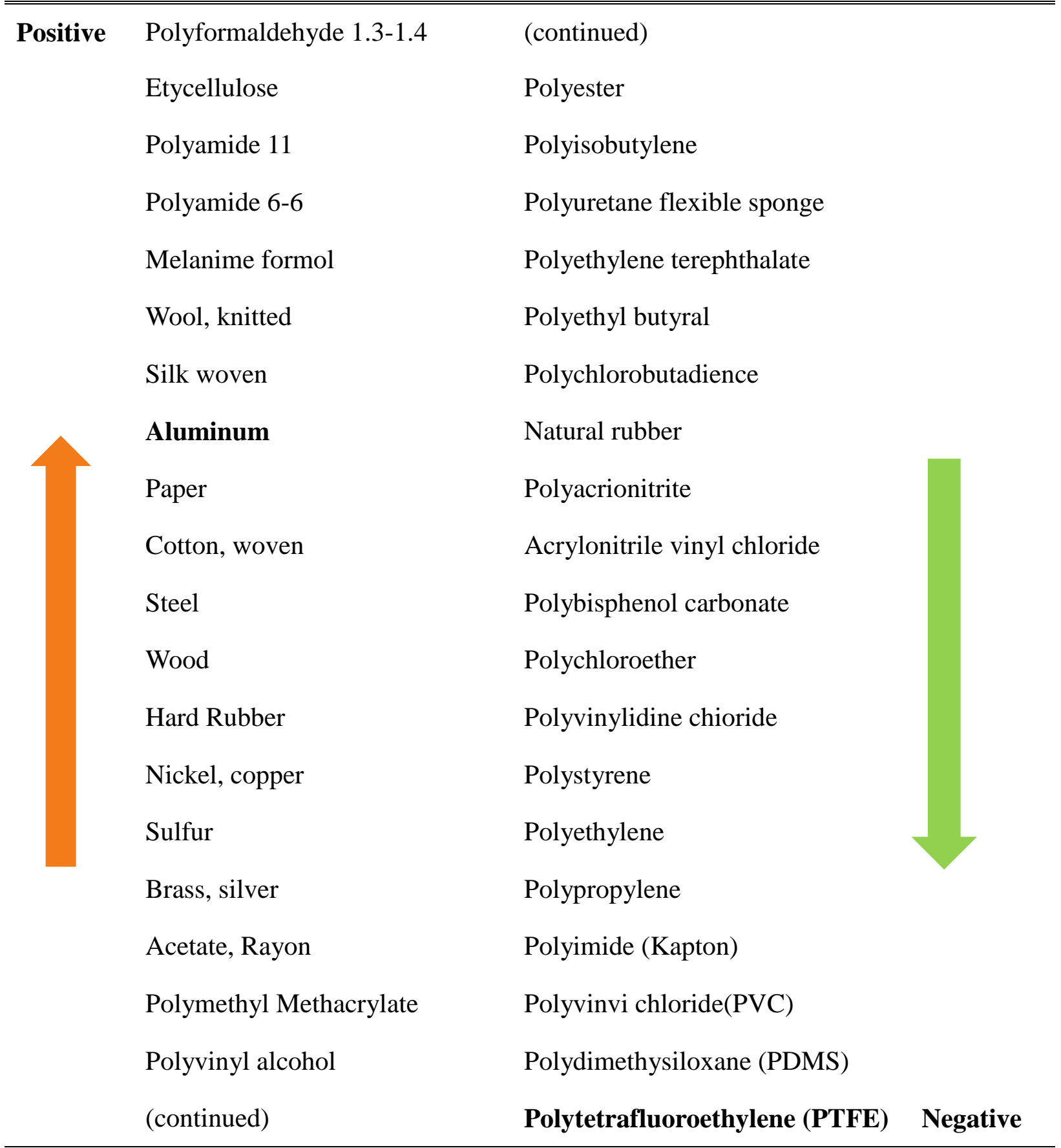

The listed materials are separated into two parts. From the table, we can see that PTFE is easy to gain electrons (negative), while Al performances reversely (positive). ${ }^{1}$ 

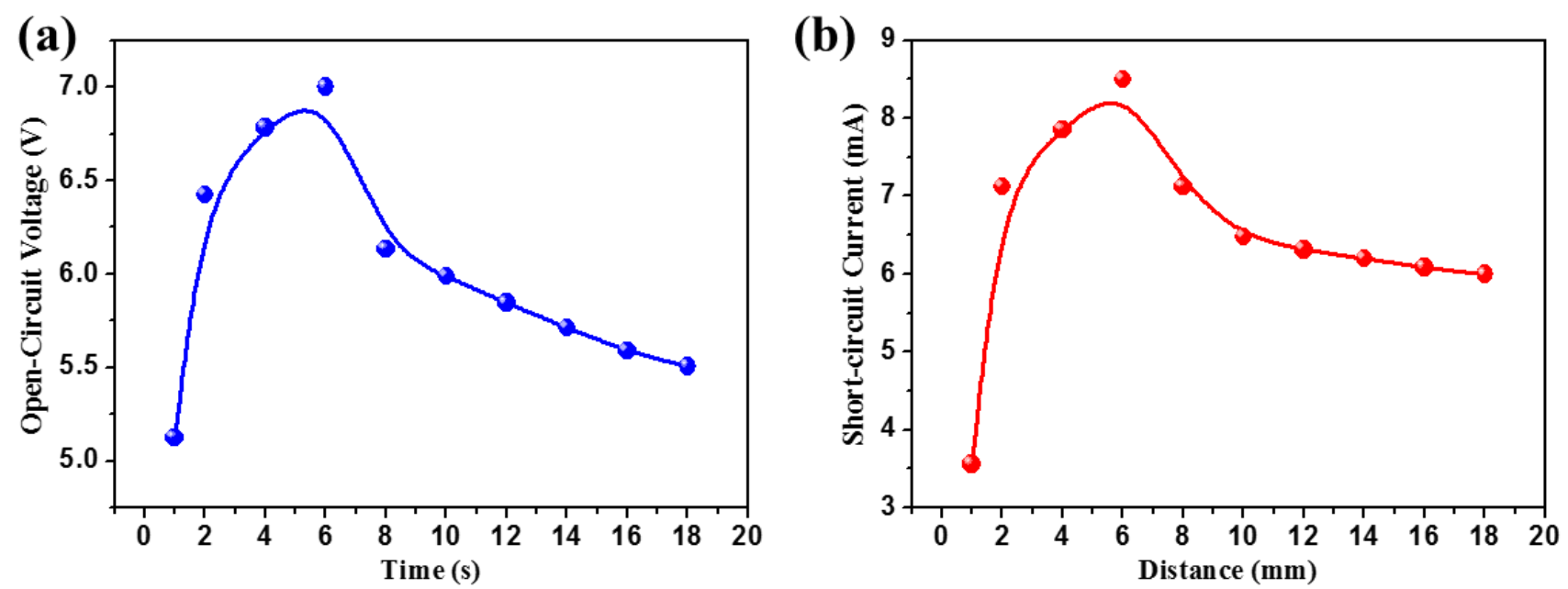

Figure S1. Open-circuit voltage (a) and short-circuit current (b) of EMG with variable distances between the middle magnet and the upper coils in a range from 1 to $18 \mathrm{~mm}$.
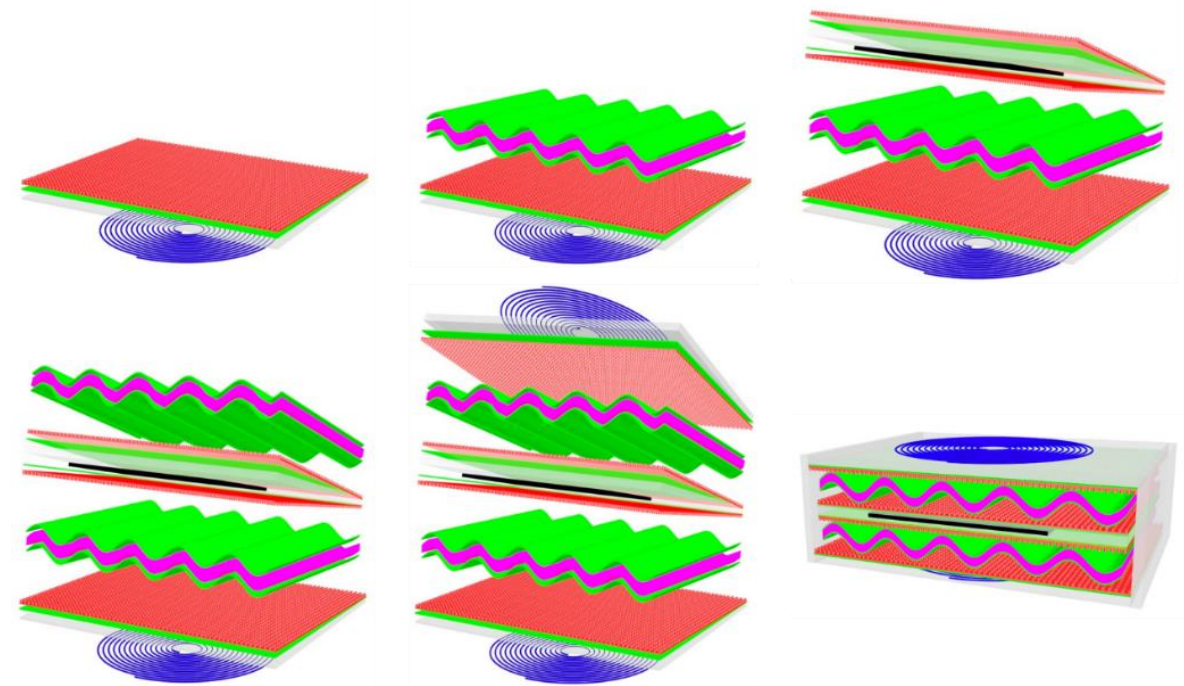

Figure S2. Schematic diagram of the designed hybridized nanogenerator.

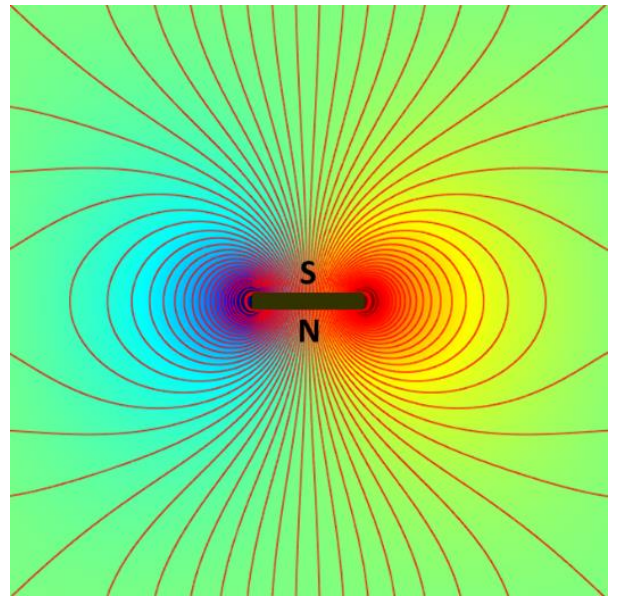

Figure S3. A 2D axisymmetric model was established by COMSOL to describe the distribution of magnetic lines. 
(a)

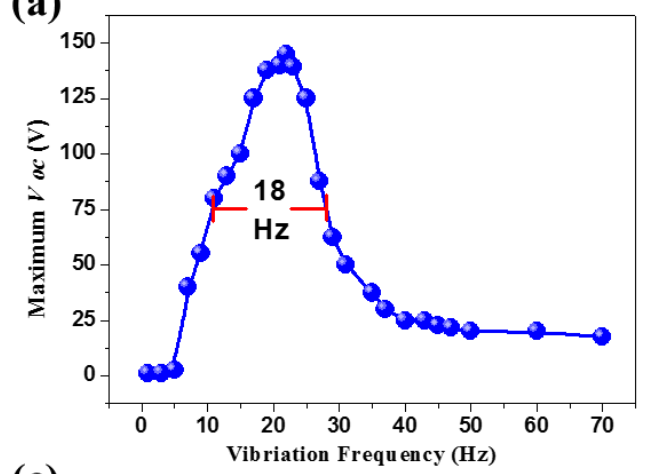

(c)

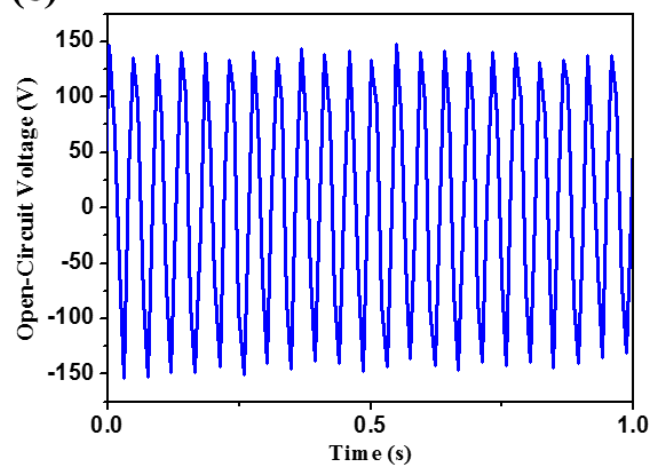

(b)

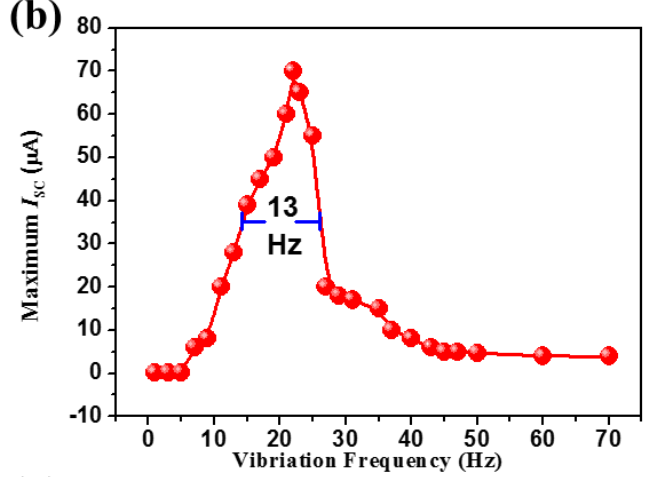

(d)

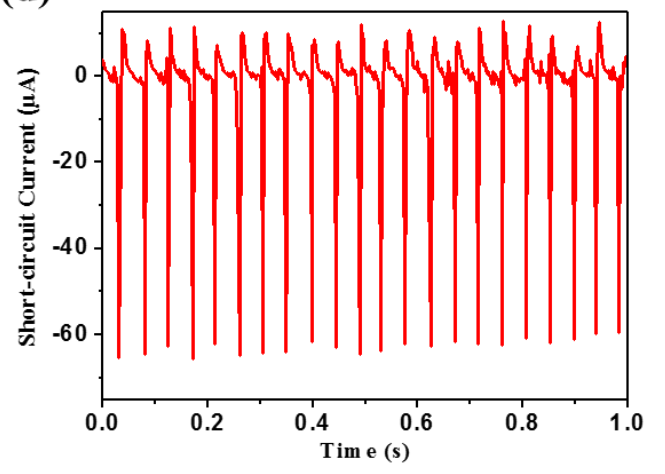

Figure S4. The output performance of the TENG. a) Open-circuit voltage $\left(V_{\mathrm{OC}}\right)$ as a function of vibration frequencies. b) Short-circuit current $\left(I_{\mathrm{SC}}\right)$ as a function of vibration frequencies. c) Open-circuit voltage $\left(V_{\mathrm{OC}}\right)$ at natural vibration frequency of $22 \mathrm{~Hz}$. d) Short-circuit current $\left(I_{\mathrm{SC}}\right)$ at natural vibration frequency of $22 \mathrm{~Hz}$. 
(a)

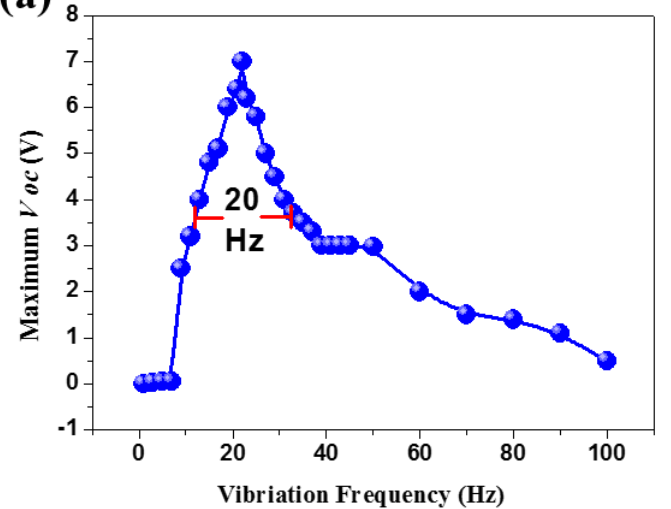

(c)

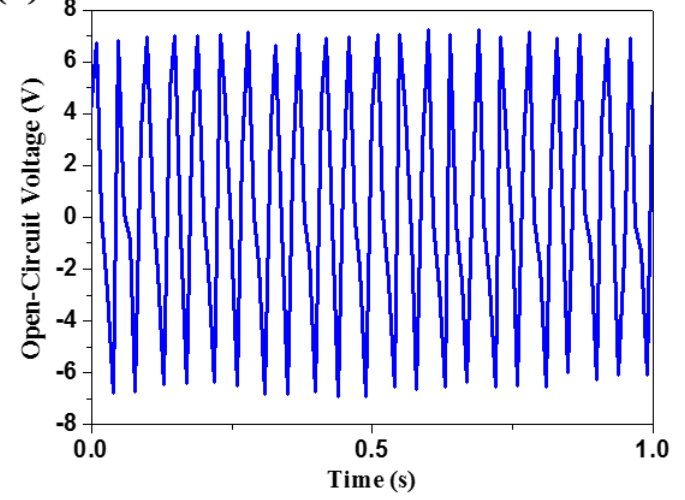

(b)

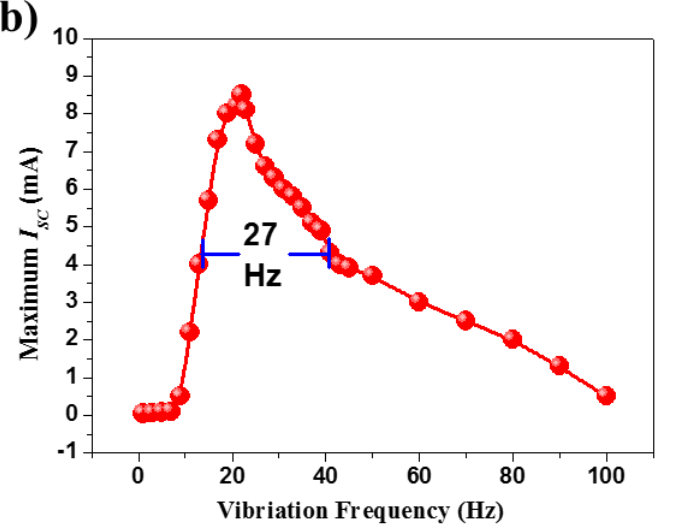

(d)

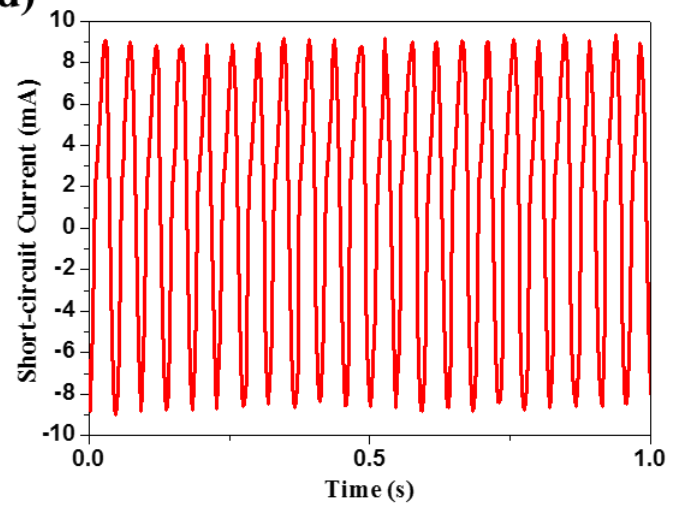

Figure S5. The output performance of the EMG. a) Open-circuit voltage $\left(V_{\mathrm{OC}}\right)$ as a function of vibration frequencies. b) Short-circuit current $\left(I_{\mathrm{SC}}\right)$ as a function of vibration frequencies. c) Open-circuit voltage $\left(V_{\mathrm{OC}}\right)$ at natural vibration frequency of $22 \mathrm{~Hz}$. d) Short-circuit current $\left(I_{\mathrm{SC}}\right)$ at natural vibration frequency of $22 \mathrm{~Hz}$.

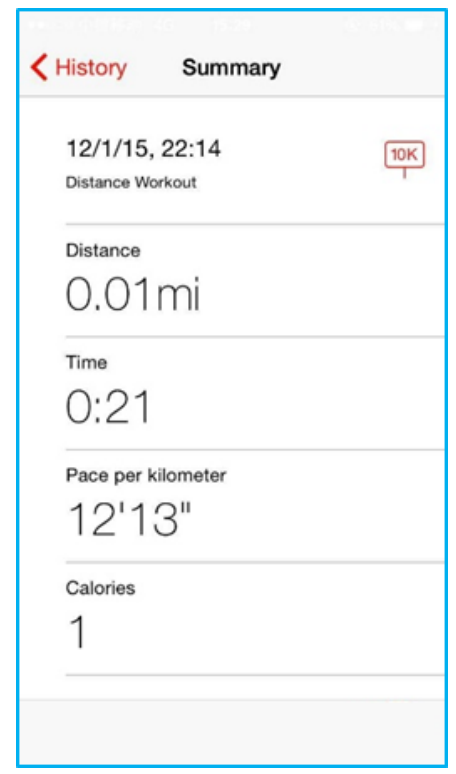

Figure S6. Data received from the pedometer on shoes after human running for 21 seconds. 

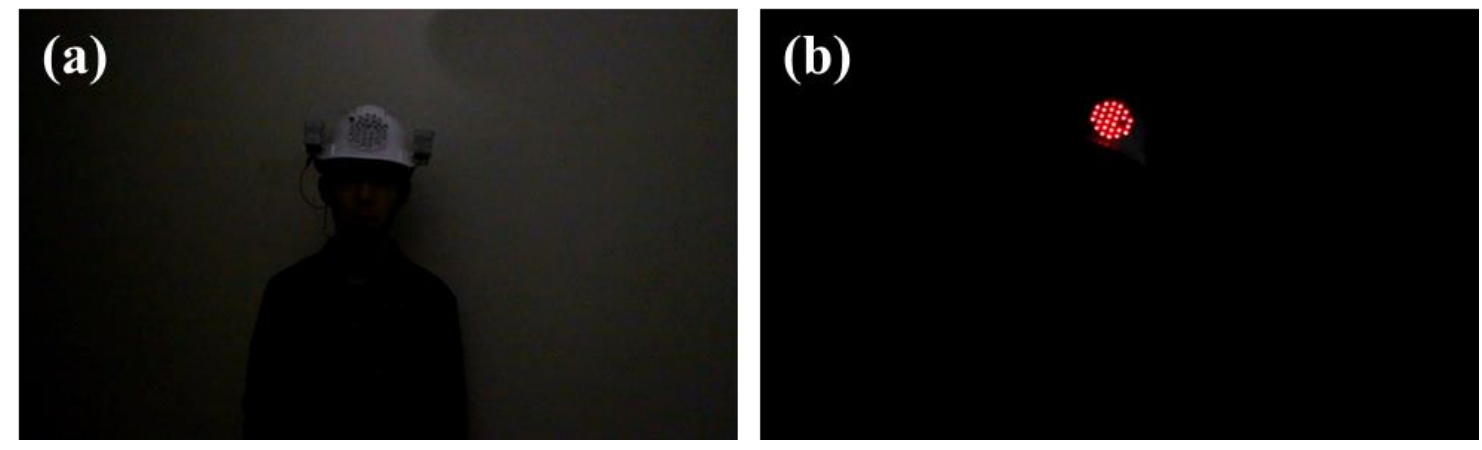

Figure S7. Photograph of the LEDs on the helmet before a) and when b) being charged by the hybridized nanogenerator.

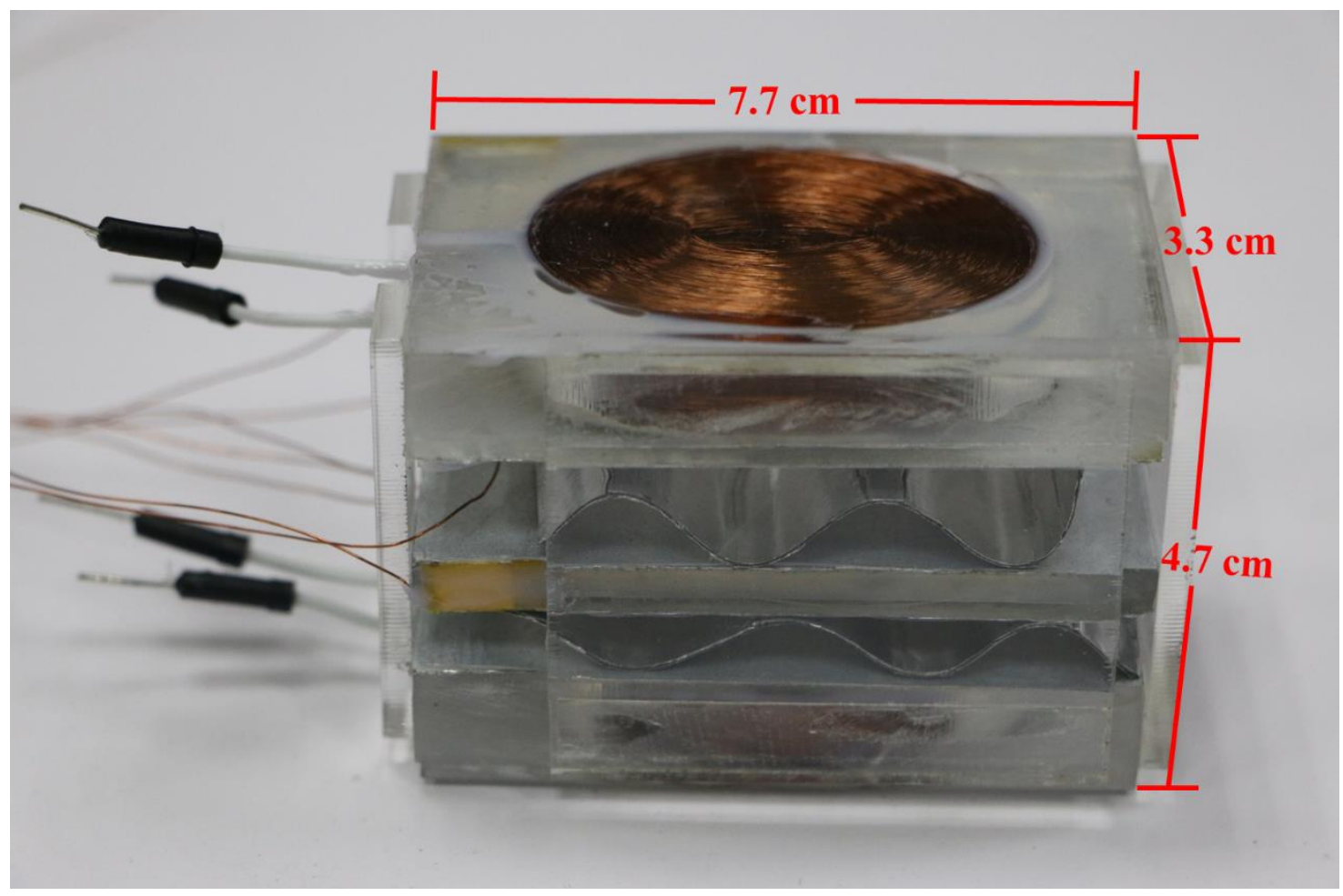

Figure S8. Photograph of the as-fabricated device with the dimension of $7.7 \mathrm{~cm} \times 4.7 \mathrm{~cm} \times 3.3 \mathrm{~cm}$. 


\section{Reference:}

1. Zhang, L.; Jin, L.; Zhang, B.; Deng, W.; Pan, H.; Tang, J.; Zhu, M.; Yang, W. Multifunctional Triboelectric Nanogenerator Based on Porous Micro-Nickel Foam to Harvest Mechanical Energy. Nano Energy 2015, 16, 516-523 